\title{
Determinants of breast cancer early detection for cues to expanded control and care: the lived experiences among women from Western Kenya
}

Joyce Kisiangani ${ }^{1,2}$, Joyce Baliddawa ${ }^{2}$, Pamela Marinda ${ }^{3}$, Hillary Mabeya ${ }^{4}$, Joseph K. Choge ${ }^{5}$, Eric Onyango Adino ${ }^{6}$ and Christopher Khayeka-Wandabwa, ${ }^{7,8^{*}}$ (1)

\begin{abstract}
Background: Estimately, 70-80\% of cancer cases are diagnosed in late stages in Kenya with breast cancer being a common cause of mortality among women where late diagnosis is the major ubiquitous concern. Numerous studies have focused on epidemiological and health policy dynamics essentially underestimating the determining factors that shape people's choices and cues to health care service uptake. The study sought to evaluate the knowledge, attitude and health seeking behavior towards breast cancer and its screening in a quest to explain why women present for prognosis and treatment when symptomatic pointers are in advanced stages, impeding primary prevention strategies.

Methods: Eight focus groups (6-10 members per group) and four key informant interviews were conducted among adult participants from rural and urban settings. Sessions were audio-recorded and transcribed. A thematic analysis of the data was based on the concepts of the health belief model. Data analysis was conducted using NVIVO10.

Results: Most women perceived breast cancer as a fatal disease and conveyed fear of having early screening. Rural women preferred self-prescribed medications and the use of alternative medicine for long periods before presenting for professional care on suspicion that the lump is cancerous. Accessibility to equipped health facilities, lack of information to establish effective follow-up treatment and low-income status were underscored as their major health seeking behavior barriers whereas, urban women identified marital status as their main barrier. Key informant interviews revealed that health communication programs emphasized more on communicable diseases. This could in part explain why there is a high rate of misconception and suspicion about breast cancer among rural and urban women in the study setting.

Conclusions: Creating breast cancer awareness alongside clear guidelines on accessing screening and treatment infrastructure is critical. It was evident, a diagnosis of breast cancer or lump brings unexpected confrontation with mortality; fear, pain, cultural barriers, emotional and financial distress. Without clear referral channels to enable those with suspicious lumps or early stage disease to get prompt diagnosis and treatment, then well-meaning awareness will not necessarily contribute to reducing morbidity and mortality.
\end{abstract}

Keywords: Breast cancer, Early breast cancer screening, Focused group discussions (FGD), Key informant interviews

\footnotetext{
* Correspondence: khayekachris@yahoo.com

${ }^{7}$ School of Pharmaceutical Science and Technology (SPST), Health Science

Platform, Tianjin University, 92 Weijin road, Nankai District, Tianjin 300072,

People's Republic of China

${ }^{8}$ African Population and Health Research Center (APHRC), P .O. Box

10787-00100, Nairobi, Kenya

Full list of author information is available at the end of the article
}

(c) The Author(s). 2018 Open Access This article is distributed under the terms of the Creative Commons Attribution 4.0 International License (http://creativecommons.org/licenses/by/4.0/), which permits unrestricted use, distribution, and reproduction in any medium, provided you give appropriate credit to the original author(s) and the source, provide a link to the Creative Commons license, and indicate if changes were made. The Creative Commons Public Domain Dedication waiver (http://creativecommons.org/publicdomain/zero/1.0/) applies to the data made available in this article, unless otherwise stated. 


\section{Background}

Cancer is the third highest cause of mortality in Kenya after infectious and cardiovascular diseases. Leading cancers are breast and cervical for women [1, 2]. Seventy to $80 \%$ of cancer cases are diagnosed in late stages. Like many other Non-Communicable Diseases (NCDs) breast cancer progresses slowly, degenerates to devastating disabilities and the management costs are high if not timely diagnosed and treated. There is better prognosis, greater chances of successful treatment and high survival rates when detected at early stages. Methods such as clinical breast exams (CBE), mammograms and breast self-examinations (BSE) have been used as main approaches $[3,4]$.

Health care access is considered a multidimensional concept encompassing both financial and non-financial dimensions $[5,6]$. It has broadly been defined as the degree of fit between a patient's socioeconomic characteristics, the health system, and health services organization $[5,6]$. The five core components of access that have been outlined are: acceptability, affordability, accessibility, accommodation, and availability [5-9]. In Kenya, tremendous gains have been made in the recent past on affordability, accommodation, and availability of cancer screening and treatment services whereas much more effort still needs to be put on accessibility and acceptability [8, 9]. Compelling findings on breast cancer in Kenya still show that most women are not aware of signs and symptoms of breast cancer due to cultural diversity views and limited education and awareness programs with a lag on clear referral channels information empowerment $[8,10-14]$. This considers the fact that, there are varied underlying information and awareness factors among Kenyan women on early cancer screening and on why and under what conditions they would take action towards medical attention for prevention or early screening and treatment $[4,15,16]$.

As studies shed more understandings on the the risks and benefits of early breast cancer screening, indepth understanding of women perceived risk and barriers have become integral $[13,17,18]$. The insights can help influence women choice of approaching early screening and treatment options or risk-reduction strategies and effective follow-up treatment [17-19] in a targeted approach that resonate with their gendered socio-cultural role; their perceived susceptibility, severity, benefits and perceived health needs $[6,20]$. The study thus generates and enhances the pool of evidence that would aid inform the development of local cancer information, education and communications (IEC) tailored for communities in Kenya incorporating approaches that fully engage the target populations [21]. As a result, potentially promote optimization of the existing and upcoming national health systems for cancer management under the vision 2030 and beyond as envisaged under the cancer awareness, community engagement plan $[6,14,21-23]$.

\section{Methods}

\section{Study design}

The qualitative research was conducted between November 2013 and March 2014. A qualitative design using focus group discussion (FGD) and key informant interview (KII) methods was applied as an ideal approach to explore perceived motivators and barriers to healthy behaviours [24]. The items in the FGD and KII were developed based on the concepts of the health belief model [16, 25-29]. Interview guide for the focus group discussions and in-depth interviews (key informants) are as provided (see Additional file 1). The concepts included; percieved severity of breast cancer, perception of susceptibility to breast cancer, perceived benefits of breast cancer early detection measures, perceived barriers to breast cancer early detection measures, self-efficacy and cues to action. The conceptual framework for the qualitative interview was adapted as earlier reported [30, 31] and is shown in Fig. 1. This approach was selected because FGDs and KIIs can be undertaken in naturalistic settings which may stimulate more openness and candor [32, 33]. Also the group interaction has the capability to elicit information and insights that are less accessible during individual interviews [34]. Probing by the moderator allowed in depth exploration of unanticipated issues as well as an opportunity to clarify and enhance understanding of responses [33].

\section{Study setting and participants}

Kakamega is a County in Western Kenya lying about 30 KM north of the Equator. The county has a population of about 1.7 million (KNBS, 2010) with a population density of about 544 people per square kilometer and is Kenya's second most populous county after Nairobi [35]. According to the 2009 census, $15.2 \%$ of the population lives in urban areas. Of the approximately 1.7 million people, $48 \%$ are male and $52 \%$ female. The population is relatively poor with a poverty rate of $53 \%$ [35]. The main health facilities in the county and its environs are: Kakamega General Hospital, Central Maternity and Nursing Home, Butere district hospital, Malava district hospital, Mumias district hospital, Matungu, Manyala and Navakholo sub-district hospitals, Kima Mission Hospital and Kimilili District Hospital.

The researcher divided the 12 constituencies into two groups; urban and rural using Kakamega First County Development Plan, 2013. Map of the study areas, Kakamega couty constituencies and study locations (see Additional file 2). Urban groups include: Mumias West, Lurambi, Shinyalu, Mumias East and Butere whereas Rural groups comprise: Matungu, Khwisero, Malava, Ikolomani, Navakholo, Lugari and Likuyani. Two constitntuencies for rural settings (Ikolomani and Likuyani) and urban settings(Mumias West and Lurambi) respectively were randomly selected. Eligible participants were selected using a purposive sampling method. Thus, for 


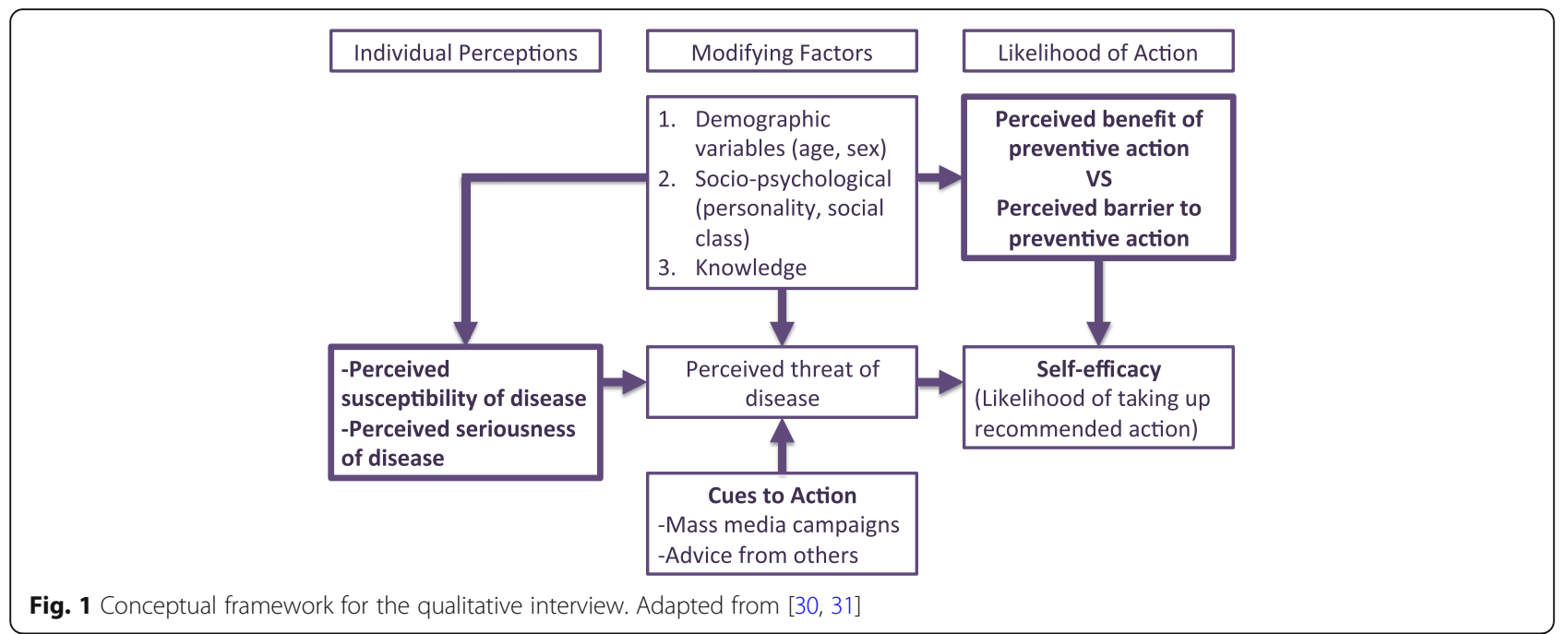

the FGDs, homogenity on particular characteristics was considered; (in this case it was for gender, age and rural or urban) and recruited from the communities of the randomly selected constituencies. Convenience sampling (number of locations and sub locations per consitutency for more objective representation) was utilized for selection of the FGDs members by the researchers with the help of local leaders (chiefs and sub-chiefs) through their documented community governance records. Thus, the FGDs were conducted in two groups: young women of age group 18-35 and older women of age group 36-60 emanating from either urban or rural concsitituency. Hence, 72 participants all above 18 years were interviewed, and comprised of four key informants and 68 members of 8 FGDs with between 6 and 10 participants per FGD. Two (2) focus groups were drawn from each constituency. For each set of 2 groups, 1 FGD constituted women of age 18-35, and another of women of age 36-60. One (1) key informant was drawn from each constituency. Key Informants were the four District Public Health Nurses (DPHN) that were from the four constituencies where the FGDs were done. The DPHN were considered because, they interact with a significant proportion of women in these communities and therefore considered to be more knowledgeable of what the women face in obtaining early breast cancer screening. Consented participants were allocated to a focus group session or Key informant interviews (KII) based on the respective eligibility cirteria.

\section{Data collection}

The items in the focus group discussion interviews and key informant interviews were developed based on the concepts of the health belief model (as above-mentioned and detailed). The concepts were pretested with small groups outside the target study area and revisions made where necessary. Information from KII (the first one to be conducted) helped inform some of the questions to ask in FGD. Thus, gaining further understanding on the validity of DPHN perspective in resonance to the population they attend to and considering they often provide inputs in appraising government health sector operational guidelines and policies which have a direct bearing on the populations they serve. Focus groups lasted between 43 to $65 \mathrm{~min}$. Rural focus groups were conducted in Swahili while discussions with urban women took place in Swahili and English. The items in FGD interviews were initially formulated in English then translated into Swahili for the use in the different study locations. Data collected in Swahili versions were translated back to English to ensure consistitency with the data collected in English versions. The five-phase cycle of compiling, disassembling, re-assembling (and arraying), interpreting and concluding were used to process the data as earlier described [36].

\section{Data analysis}

All the data from the KIIs and FGDs were then uploaded to the Computer Assisted Qualitative Data Analysis Software (CAQDAS) QSR Nvivo10 for windows for management and analysis. Coding was done as earlier described [36] with level 1 to level 3 coding with the following major emerging categories from the level three coding: health seeking behavior of breast cancer and its screening, knowledge of breast cancer and its screening, attitude towards breast cancer and its screening and breast health promotional strategies. Comparisons between the four groups; urban rural, 18-35 year old women and those aged 36-60 years were made as categories emerged. Findings were reported per the themes/topics that emerged. 


\section{Results}

Findings from the focus group discussions and key informant interviews are presented per the main categories from level 3 coding that emerged.

\section{Category one: Health seeking behavior of breast cancer and its screening}

Sixty-eight women aged 18-60 years (age: 18-35: 36 and 36-60: 32) from the selected rural and urban constituencies of Kakamega county Kenya participated in eight focus groups (average 8.5 participants per group). Of these 63 (92.6\%) were Christians and $5(7.4 \%)$ were Muslims. Participants were predominantly married (72.1\%). The educational level of the respondents varied considerably; $45.6 \%$ had primary education, $35.3 \%$ secondary, $11.8 \%$ middle level college training and $2.9 \%$ university degree while the rest had no formal schooling. There were 32 women from the rural setting and 36 urban. The average family size was 6 persons, with an average of 4 children per woman. All working women had government medical cover, the National Health Insurance Fund (NHIF) through their jobs, granting coverage for health service use at governmental facilities for themselves and their dependents. Despite having NHIF cover, the women expressed a generalized preference for private health care providers. They however explained that, their choice to use public rather than private services was often mediated by a series of social, economic, and geographical considerations. None of the women had private health insurance cover instead self-help savings and credit groups, commonly known as chamas were common source of building financial capacity and borrowing among the women. The vast majority of women rated their health status as good.

There were disparities between the urban and rural when it came to health seeking behavior barriers (see Additional file 3). Most urban women (from all the 4 urban FGDs) identified marital status as their major barrier to early breast cancer screening. Specifically, young-urban women explained that married women have to consult and at times get not only advice but also permission from their husbands before seeking any medical help or undertaking social commitments that has an impact on their health. An urban woman from group 7 to symbolically contextualize the challenge depth narrated:

"Some men do not allow their women to go to the hospital. Most men do not even allow their women to go out of the homestead and 'fetch water for domestic use, how then will they even allow women to go for cancer screening at the hospital?"

They went further to explain that as the head of the home, some husbands would have difficulties in allowing their women to go for cancer screening as it is a disease that is associated with terminal health complications equating it to be even more worse than HIV/AIDS and getting to know makes it even more hard to live with the new reality. Contrary, rural women (up to $75 \%$ of rural participants) identified long distance to health facility, lack of information on breast cancer and its screening and low-income status as major health seeking behavior barriers. An older woman from rural group 4 said:

"Ignorance and lack of information on the importance of cancer screening hinders women from seeking early breast cancer screening".

A younger woman from rural group 1, said:

"The long distance to the cancer facility would cost a lot of transport fare that I cannot afford and this makes it difficult for me."

An interview with Key informant revealed that the health centres and hospitals do not have enough nurses to perform regular breast cancer screening. She narrated:

\section{"The number of staff in the hospitals should be} increased. Sometimes you will find there is only one nurse who has to do everything in a hospital. When a woman comes in for a BCS, the nurse is most likely to attend to the patients whose lives are at risk first. There should be devolution. The number of staff should be increased."

Through indepth discussions it was evident cultural religion orientation was a contributing barrier among rural women compared to their urban counterparts. A rural participant from rural group 3 said;

"Some women go to churches that believe in prayers for healing, the churches do not allow their followers to go to the hospital. Such women do not go for breast cancer screening."

The study further revealed that most women are skeptical of having early breast cancer screening as attributed to fear of getting a positive breast cancer diagnosis; stigmatization associated with it and breast cancer related cultural beliefs alongside misconceptions as well as the, what next? doubts. The action taken when a woman realized she had a breast lump was influenced by the community perception of the origin of the disease for the older urban participants, conventional practices and beliefs for most rural participants and level of knowledge by younger-rural women. Most urban women described the community perception and association of breast cancer to promiscuity, infidelity, and 
equating it to HIV/AIDS thus hindering women who suspected a lump in their breast was cancerous from seeking early treatment in hospitals. An older woman from the urban group 8 narrated:

"If a woman is known to be sleeping around with many men, and she discovers that she has breast cancer, she will prefer not to go and seek treatment because she is afraid that she might go to the hospital, get tested for HIV and told that she has AIDS."

Rural women on the other hand preferred using herbal remedies, self-medicating with painkillers or going to traditional medicine men for complementary and alternative remedy when they suspected they had a cancerous lump in their breast. A woman from rural group 3 said:

"Women believe it is a sore, so we take traditional herbs called "miyeka".

We also established that younger-rural participants and older participants were not aware or clear of simple methods such as breast self-examination or where they could get early breast-screening services. Several older participants asked to be taught how to detect a lump in their breast while younger women explained that they were not confident on performing breast self-examination on themselves. A young participant explained in frustration how nurses instructed them to palpate their breast but she did not understand how palpation was done or what the nurses meant by palpate. When asked how to check for lumps in their breast, a participant from urban group 8 said:

"We do not know. You should teach us on how one knows that they have breast cancer."

This is despite the fact that health centres in Kakamega County schedule a day in a month for breast health education. A key informant from a rural group explained that most facilities in the county conduct breast screening at facility level once a month. However, she also added that it was likely that women did not know that they could access such services for free due to lack of information.

\section{Category two: Knowledge of breast cancer and its screening}

Younger participants seemed to have a better comprehension of breast cancer, its early manifestations, early breast cancer screening and predispositions' to the disease compared to older participants. A participant from rural group 1 defined breast cancer as:
"I know they are cells that multiply in the breast leading to death."

Specifically, young urban participants seemed more knowledgeable about lifestyle issues that predispose individuals to breast cancer. They mentioned smoking, too much sugar and salt in food, use of bleaching pills and self-medicated pills. A woman in urban group 7 said:

\section{"I know that it is brought about by smoking and using} a lot of fat in your food."

Other misconceptions across the women included being born with "risky bugs" in their breasts, breast cancer being a consequence of having HIV and prostitution as well as surgery of the breast being associated with breast cancer status and death.

\section{Category three: Attitudes of women toward breast cancer and its screening}

Most women were concerned of breast cancer and were overwhelmingly convinced that it is a serious terminal disease with no cure. Terms such as 'deadly and death' were commonly used in the description of breast cancer. A participant in rural group 2 said:

"Breast cancer is a death sentence."

Another participant in rural group 1 said:

"I understand that it has no cure. It is an incurable disease."

Several participants also described the perceived seriousness of the disease as extremely dangerous and incurable. A young woman in urban group 5 stated:

"The women in the community believe that breast cancer is a disease that does not have a cure and so will not bother to go to the hospital."

Participants were also afraid of CBE. A participant from urban group 8 narrated:

"I do not think going for breast cancer screening is a necessity. One woman that I know went for breast cancer screening and was told that she had it and that her breast had to be removed... When her breast was cut, the cancer spread throughout her body and following that, I and many of my friends who knew her can't go to the hospital."

Some urban participants seemed well aware of the benefits of early breast cancer screening. They noted that 
knowing their breast cancer status early would result to the early treatment of the disease and this would increase the chances of survival. They also explained how early screening uptake reduces the high cost of treatment of the disease if it is detected early. A woman from urban group 6 said:

"If I am found with cancer at an early stage, it means that I will not spend much on the treatment of the disease. It will be cheaper for me."

Despite this knowledge among some of the participants, they were still sceptical of having early breast cancer screening as it would lead to psychological stress, depression and even early death unlike when they were not aware.

\section{Category four: Breast health promotion strategies}

Most of the participants had very limited knowledge of breast health awareness programs. Participants could only mention programs aimed at communicable diseases (Malaria and HIV) awareness creation. Participants from rural group 2 said:

\section{"There is no much emphasis on breast cancer awareness campaigns."}

The participants pointed out the reason why they do not have much information on breast cancer was because it was not being given as much prominence as other diseases like malaria per their views on assessment of public health information availed to them most of the times. An interview with a key informant from urban setting revealed that if participants were given information on breast cancer and its screening; there would be rapid uptake of early breast cancer screening among women. She said:

"In this community, if a woman does not know the importance of early breast cancer screening, they will not go for screening. But after they have been taught on the importance, many of them flock to the screening rooms and get screened for cancer. An example is cervical cancer. Most women have had a pap smear done on them because there have been consistent seminars and campaigns on the importance of doing a pap."

An urban participant in group 5 when asked what measures can be put in to motivate women to go for early screening said:

"If they gave us information on breast cancer, it would motivate me to go for screening."
The participants also asked for free and regular breast cancer screening services to be made available not only in mother-child health clinics but also in the overall hospitals services. When the women were asked on the best channel of communication of information on breast cancer and its screening, urban participants suggested the use of media, and mother-child health clinics. Most young participants suggested use of community health workers (CHW), social media and text messages as the best avenues for the communication of information. Rural participants suggested the use of community health workers. A rural participant said:

\section{"Through seminars- they should take CHW's on seminars, and when they come they should educate the community on breast cancer by doing door to door education."}

Older women suggested use of door to door education, churches, village meetings (barazas) and village chief's as the best channel for communication of information on breast cancer and its screening. Key informant 2 suggested:

\section{"Verbal health education- use of wall charts, the mass media, chief barazas and use community leaders (church leaders and chiefs to talk to them)."}

\section{Discussion}

In the presented findings, there were disparities between urban and rural women when it came to knowledge, attitude and health seeking behavior towards breast cancer and its screening. Whereas urban women identified concerns such as partner related consensus, rural women mostly identified the lack of information, long distance to health facilities, long waiting lines in hospitals, financial constrains (lack of transport fares, high treatment/screening costs) and lack of health professionals to perform needed screening tests as barriers to breast cancer screening. In the recent past, gainful strides have been achieved in availing a more inclusive health insurance cover, increased adaptation of treatment guidelines, expansion and upgrading of radiotherapy equipment across the country in addition to more research opportunities [9, 21, 37]. However, even with governments efforts, the uptake of these services remains low and/or delayed over time [21, 38]. For instance, out of every seven women in Kenya, six have not been screened for breast cancer $[15,16]$. The disease strikes 1 in 9 women due to late diagnosis according to the Kenya National Cancer Control strategy and as observed on burden of breast cancer and contributing factors of high mortality [23, 39-41]. Most women hardly seek professional medical attention untill symptomatic pointers are advanced [42]. It was observed in the FGDs while some urban women opted to seeking treatment in health facilities when they 
discovered that they had a lump in their breast, most rural women and some urban women prefered to seek care from complementary and alternative medicine providers or ignore the lump hoping it would clear off.

Against the backdrop of improvement efforts, the present findings still mirror earlier observations of low uptake and with socio-economic factors of health having been implicated in influencing individuals and communities' health seeking behaviors [1, 43]. Further evidence that correspond to the present study points to lack of awareness, insufficient financial resources, worry about examination discomfort, fear of finding cancer due to associated myths and stigma, and inability to establish effective follow-up treatment $[14,15,18,20]$. The barriers reported by the rural participants in the current study could be attributed to the fact that most rural areas are usually characterized by low population density and residents have poor access to health care than their urban setting counterparts as earlier observed [44]. Furthermore, according to WHO (2007) study on the social determinants of health, lack of knowledge and awareness to health is a great barrier in seeking health among women as well as stigmatization associated with breast cancer, fear, and fear of rejection by marital partners as a result of being diagnosed with the disease [45].The aspect underpins the need for family, partner involvement and both gender targeted approaches in promoting awareness which has been the effort to enhanced success of other programmes like the fight against HIV [46].

Among the urban women, decision to visit a health facility on the discovery they had breast cancer was influenced by their knowledge and information about breast cancer. Women who are knowledgeable about breast cancer and its risk factors are known to be more likely to comply with such early detection behaviors than those who are not [47]. Rural women decisions are influenced by lack of information on breast cancer with one of the leading factors to late presentation being lack of awareness about benefits of early detection of breast cancer as observed in varied setting and colloborated by the presented findings [48-51]. Consequently, there are high indications that women have misconceptions on breast cancer and its screening because they cannot access health information [12, 15]. This line of thought is reinforced by the Kenya Cancer Research and Control National Stakeholder Meeting action points that highlight: 1) Engaging community leaders and members to identify key drivers of stigma through Knowledge, Attitude, and Practice (KAP) studies, 2) Developing culturally appropriate messages to address perceptions and knowledge gaps, 3) Coordinating knowledge sharing about community education efforts and 4) Raising public awareness about cancer prevention and early detection, targeting $60 \%$ of the population by 2018. Incidences of breast cancer have been observed to be low among rural women however, death rates are higher among those diagnosed with the complication [44]. The high death rate among rural women diagnosed could be attributed to their fear and perception about the disease (it would lead to further spread, death, and loss of their position in the society as women). The presented findings on perceived severity were comparable to preceding assesesments $[15,16]$ despite the varied geographical and cultural settings.

\section{Conclusion}

Creating breast cancer awareness alongside clear guidelines on accessing screening and treatment infrastructure is critical. The messaging should aim at instilling hope and eradicating the myths and misconseptions harboured about the disease. It was evident, a diagnosis of breast cancer/ lump with lack of clear course of expertise support, brings unpexpected confrontation with mortality; the fear, pain, cultural barriers, emotional and financial distress are very real. Without clear referral channels to enable those with suspicious lumps or early stage disease to get prompt diagnosis and treatment, then well-meaning awareness will not necessarrily contribute to reducing morbidity and mortality.

\section{Additional files}

Additional file 1: Interview guide for the focus group discussions and in-depth interviews (key informants) (DOCX $44 \mathrm{~kb}$ )

Additional file 2: Map of the study areas. (DOCX $2073 \mathrm{~kb}$ )

Additional file 3: Perceived barriers to early breast cancer screening uptake and treatment as mentioned by FGD participants. (DOCX $18 \mathrm{~kb}$ )

\section{Abbreviations}

BSE: Breast self-examinations; CBE: Clinical breast exams; DPHN: District Public Health Nurses; FGD: Focus group discussion; HBM: Health belief model; IEC: Information, education and communications; KIl: Key informant interview; NCDs: Non-communicable diseases

\section{Acknowledgements}

The authors would like to thank the focus group and KII participants as well as the county and sub-county administrators for their time, help and feedback in the implementation phase of the project.

\section{Availability of data and materials}

We have presented all our main data in the form of themes and tables. The datasets supporting the conclusions of this article are included within the article (and its Additional files).

\section{Authors' contributions \\ JK, CKW and PM conceptualized the manuscript and designed plan of analysis. JK, PM, JKC, EOA and CKW conducted the analysis and wrote the manuscript, which was later reviewed by all the authors. In addition, JK, JB, $\mathrm{HM}$ and CKW led the major population-based study that provided the data source for this paper. All authors read and approved the final manuscript.}

\section{Ethics approval and consent to participate}

The conduct and reporting presented in this paper adhered to the consolidated criteria for reporting qualitative research (COREQ) guidelines [52]. Ethical approval to carry out the study was obtained from the Moi Teaching and Referral hospital Institutional Research and Ethics Committee (IREC). Formal Approval Number: FAN: IREC 1058. Written informed consent was also obtained from each study participant. All aspects of the study were conducted in accordance with the approved protocol. 


\section{Competing interests}

The authors declare that they have no competing interests.

\section{Publisher's Note}

Springer Nature remains neutral with regard to jurisdictional claims in published maps and institutional affiliations.

\section{Author details}

${ }^{1}$ The Aquaya Institute, Nairobi 00505, Kenya. ${ }^{2}$ School of Public Health, Department of Epidemiology and disease control, Moi University, P.O. Box 3900, Eldoret, Kenya. ${ }^{3}$ Department of Food Science and Nutrition, School of Agricultural Sciences, The University of Zambia, Lusaka, Zambia. ${ }^{4}$ Gynocare Fistula Centre, Eldoret Hospital Lane, P.O. BOX 2326-30100, Eldoret, Kenya. ${ }^{5}$ University of Kabianga, P.O. Box 2030-20200, Kericho, Kenya. ${ }^{6}$ East African Breweries Limited, Nairobi, Kenya. ${ }^{7}$ School of Pharmaceutical Science and Technology (SPST), Health Science Platform, Tianjin University, 92 Weijin road, Nankai District, Tianjin 300072, People's Republic of China. ${ }^{8}$ African Population and Health Research Center (APHRC), P .O. Box 10787-00100, Nairobi, Kenya.

\section{Received: 17 April 2016 Accepted: 18 May 2018}

\section{Published online: 01 June 2018}

\section{References}

1. Merletti F, Galassi C, Spadea T. The socioeconomic determinants of cancer Environ Health. 2011;10(Suppl 1):S7.

2. Ly M, Antoine M, André F, Callard P, Bernaudin J-F, Diallo DA. Breast cancer in sub-Saharan African women: review. Bull Cancer. 2011;98(7):797-806.

3. Lopez ME: The Association of Religiosity and use of breast Cancer screening among older women in Latin America and the Caribbean. 2009.

4. Busakhala NW, Chite FA, Wachira J, Naanyu V, Kisuya JW, Keter A, Mwangi A, Njiru E, Chumba D, Lumarai L. Screening by clinical breast examination in western Kenya: who comes? J Global Oncol. 2016;2(3):114-22.

5. Kullgren JT, McLaughlin CG. Beyond affordability: the impact of nonfinancial barriers on access for uninsured adults in three diverse communities. J Community Health. 2010;35(3):240-8.

6. Unger-Saldaña K. Challenges to the early diagnosis and treatment of breast cancer in developing countries. World J Clin Oncol. 2014;5(3):465.

7. Penchansky R, Thomas JW. The concept of access: definition and relationship to consumer satisfaction. Med Care. 1981;19:127-40.

8. Topazian H, Cira M, Dawsey SM, Kibachio J, Kocholla L, Wangai M, Welch J, Williams MJ, Duncan K, Galassi A. Joining forces to overcome cancer: the Kenya cancer research and control stakeholder program. J Cancer Policy. 2016;7:36-41.

9. Vanderpuye V, Grover S, Hammad N, Simonds H, Olopade F, Stefan D. An update on the management of breast cancer in Africa. Infect Agents Cancer. 2017;12(1):13.

10. Korir A, Okerosi N, Ronoh V, Mutuma G, Parkin M. Incidence of cancer in Nairobi, Kenya (2004-2008). Int J Cancer. 2015;137(9):2053-9.

11. Kantelhardt E, Muluken G, Sefonias G, Wondimu A, Gebert H, Unverzagt S, Addissie A. A review on breast cancer care in Africa. Breast Care. 2015;10(6):364-70.

12. Naanyu V, Asirwa CF, Wachira J, Busakhala N, Kisuya J, Otieno G, Keter A, Mwangi A, Omenge OE, Inui T. Lay perceptions of breast cancer in western Kenya. World J Clin Oncol. 2015;6(5):147.

13. Kisuya J, Wachira J, Busakhala N, Naanyu V, Chite A, Omenge O, Otieno G, Keter A, Mwangi A, Inui T. Impact of an educational intervention on breast cancer knowledge in western Kenya. Health Educ Res. 2015;30(5):786-96.

14. Asiki G, Shao S, Wainana C, Khayeka-Wandabwa C, Haregu TN, Juma PA Mohammed S, Wambui D, Gong E, Yan LL. Policy environment for prevention, control and management of cardiovascular diseases in primary health care in Kenya. BMC Health Serv Res. 2018;18(1):344.

15. Muthoni A, Miller AN. An exploration of rural and urban Kenyan women's knowledge and attitudes regarding breast cancer and breast cancer early detection measures. Health Care Women Int. 2010;31(9):801-16.

16. Paul M. Factors that Influence the uptake of Breast Cancer Screening among Women of Reproductive Age in Mosocho Division. Kisii Central District: Kenyatta University; 2012.

17. de Jonge E, Vlasselaer J, Van de Putte G, Schobbens J-C. The construct of breast cancer risk perception: need for a better risk communication? Facts Views Vis Obgyn. 2009;1(2):122.
18. Mosavel M, Simon C, Ahmed R. Cancer perceptions of south African mothers and daughters: implications for health promotion programs. Health Care Women Int. 2010;31(9):784-800.

19. Urcuyo KR, Boyers AE, Carver CS, Antoni MH. Finding benefit in breast cancer: relations with personality, coping, and concurrent well-being. Psychol Health. 2005;20(2):175-92.

20. Jones CE, Maben J, Jack RH, Davies EA, Forbes LJ, Lucas G, Ream E. A systematic review of barriers to early presentation and diagnosis with breast cancer among black women. BMJ Open. 2014;4(2):e004076.

21. Cira M: Joining forces to overcome cancer: the Kenya cancer research and control stakeholder Program 2015.

22. Commission NP: National development plan vision 2030. 2013.

23. Akuoko CP, Armah E, Sarpong T, Quansah DY, Amankwaa I, Boateng D. Barriers to early presentation and diagnosis of breast cancer among African women living in sub-Saharan Africa. PLoS One. 2017:12(2):e0171024.

24. Morgan DL. Successful focus groups: advancing the state of the art, vol. 156. Thousand Oaks: Sage publications; 1993.

25. Janz NK, Becker MH. The health belief model: a decade later. Health Educ Behav. 1984;11(1):1-47.

26. Champion VL, Skinner CS. The health belief model. Health Behav Health Educ: Theory, Research, and Practice. 2008;4:45-65.

27. Parsa P, Kandiah M, Mohd Nasir M, Hejar A, Nor Afiah M. Reliability and validity of Champion's health belief model scale for breast cancer screening among Malaysian women. Singap Med J. 2008;49(11):897.

28. Hashemian M, Amin Shokravi F, Lamyian M, Hassanpour K, Akaberi A. Reliability and validity of the Champion's health belief model scale for mammography among Iranian women with family history of breast Cancer. Health Educ Health Promotion. 2014;1:19-31.

29. Zelviene A, Bogusevicius A. Reliability and validity of the Champion's health belief model scale among Lithuanian women. Cancer Nurs. 2007;30(3):E20-8.

30. Rosenstock IM. Why people use health services. Milbank Q. 2005;83(4) https://doi.org/10.1111/j.1468-0009.2005.00425.x. PMCID: PMC2690262.

31. Rosenstock I. Why people use health services. The Millbank Memorial Fund O. 1966:44:94-127.

32. Johnson RB, Onwuegbuzie AJ. Mixed methods research: a research paradigm whose time has come. Educ Res. 2004;33(7):14-26.

33. Krueger RA. Focus groups: a practical guide for applied research ( 2 nd ed.). Thousand Oaks: Sage Publications; 1994.

34. Morgan DL, Krueger RA: When to use focus groups and why. 1993.

35. KNBoS. Kenya Demographic and Health Survey 2008-09, vol. 2010. Nairobi: Kenya National Bureau of Statistics.

36. Yin R. Qual Res from start to finish. New York: Guilford Press; 2011.

37. Strother R, Asirwa F, Busakhala N, Njiru E, Orang'o E, Njuguna F, Skiles J, Carter J, Mega A, Kaspers G: The evolution of comprehensive cancer care in western Kenya. J Cancer Policy 2013, 1(1):e25-e30.

38. Akinyemiju TF. Socio-economic and health access determinants of breast and cervical cancer screening in low-income countries: analysis of the world health survey. PLoS One. 2012;7(11):e48834

39. Dunn J, Holland J, Hyde MK, Watson M. Psycho-oncology and primary prevention in cancer control plans: an absent voice? Psycho-Oncology. 2015:24(10):1338-45.

40. Kallestrup P: A civil society benchmark report: Responses to NCDS in East Africa. 2014

41. Asima FC, Greist A, Busakhala N, Rosen B, Loehrer PJ. Medical education and training: building in-country capacity at all levels. J Clin Oncol. 2016:34(1):36-42

42. El Saghir NS, Adebamowo CA, Anderson BO, Carlson RW, Bird PA, Corbex M, Badwe RA, Bushnaq MA, Eniu A, Gralow JR. Breast cancer management in low resource countries ( $\mathrm{LRCS}$ ): consensus statement from the breast health global initiative. Breast. 2011;20:S3-S11.

43. Akinyemiju TF: Socio-economic and health access determinants of breast and cervical cancer screening in low-income countries: analysis of the world health survey. 2012.

44. Leung J, McKenzie S, Martin J, McLaughlin D. Effect of rurality on screening for breast cancer: a systematic review and meta-analysis comparing mammography. Rural Remote Health. 2014;14:2730.2731-13.

45. Sen G, Ostlin P, George A: Unequal unfair ineffective and inefficient. Gender inequity in health: Why it exists and how we can change it. Final report to the WHO Commission on Social Determinants of Health. 2007.

46. Marinda P, Chibwe N, Tambo E, Lulanga S, Khayeka-Wandabwa C. Challenges and opportunities of optimal breastfeeding in the context of HIV option B+ guidelines. BMC Public Health. 2017;17(1):541. 
47. Pearlman DN, Clark MA, Rakowski W, Ehrich B. Screening for breast and cervical cancers: the importance of knowledge and perceived cancer survivability. Women Health. 1999;28(4):93-112.

48. Jemal A, Bray F, Forman D, O'Brien M, Ferlay J, Center M, Parkin DM. Cancer burden in Africa and opportunities for prevention. Cancer. 2012;118(18):4372-84.

49. Ndwiga C, Abuya T, Mutemwa R, Kimani JK, Colombini M, Mayhew S, Baird A, Muia RW, Kivunaga J, Warren CE. Exploring experiences in peer mentoring as a strategy for capacity building in sexual reproductive health and HIV service integration in Kenya. BMC Health Serv Res. 2014;14(1):1.

50. Sambo L, Dangou J, Adebamowo C, Albrecht C, Gombé-Mbalawa C, Ngoma T, Moeti M, Sambo B. Cancer in Africa: a preventable public health crisis. J Africain du cancer/African J Cancer. 2012;4(2):127-36.

51. de Souza JA, Hunt B, Asirwa FC, Adebamowo C, Lopes G. Global Health equity: Cancer care outcome disparities in high-, middle-, and low-income countries. J Clin Oncol. 2016;34(1):6-13.

52. Tong A, Sainsbury P, Craig J. Consolidated criteria for reporting qualitative research (COREQ): a 32-item checklist for interviews and focus groups. Int J Qual Health Care. 2007;19(6):349-57.

Ready to submit your research? Choose BMC and benefit from:

- fast, convenient online submission

- thorough peer review by experienced researchers in your field

- rapid publication on acceptance

- support for research data, including large and complex data types

- gold Open Access which fosters wider collaboration and increased citations

- maximum visibility for your research: over $100 \mathrm{M}$ website views per year

At BMC, research is always in progress.

Learn more biomedcentral.com/submissions 